\title{
Between Altruism and Narcissism: An Action Theoretical Approach of Personal Homepages Devoted to Existential Meaning
}

\author{
ELLEN HIJMANS and MARTINE VAN SELM
}

\section{Abstract}

This article aims to examine existential meaning constructions from an action theoretical perspective in a specific Internet environment: the personal homepage. Personal homepages are on-line multi-media documents addressing the question 'Who am I?' Authors of personal homepages provide information on both their personal and public identity. These identity constructions sometimes include reflections on the meaning of life. Answers to questions on the meaning of life reflect the way in which individuals assign ultimate meanings to human life, and consist of three key components: orientation (goals and objectives), beliefs, and experience. This paper aims to examine existential meaning constructions from a action theoretical perspective in a specific Internet environment: the personal homepage. Findings are reported of a qualitative content analysis of answers to the meaning of life provided in a sample of 42 personal homepages. We found that most answers to the meaning of life could be interpreted either as 'divine/religious', 'experience centered', 'cosmic', or 'social utopian'. The answers provided on the homepages showed similarities with findings reported in other studies on existential meaning. In addition, we found that this Internet environment offers new venues for expressing orientation (goals and objectives), beliefs, and experience reflecting answers to the meaning of life.

Keywords: Action theoretical approach in communicative research, personal hompages, identity constructions, existential meaning

\section{Existential meaning, Internet and personal homepages}

In this article a first exploration is presented which is aimed at characterizing existential meaning as presented on a selection of personal homepages. At first sight the domains of existential meaning and the Internet 
do not seem to have much in common. In fact, often the opposite, such as meaninglessness or alienation, is associated with the consequences of information and communication technology (Ruffin, 1984; Gergen, 1991). In our contribution we nevertheless want to consider the possibilities for existential meaning on the Internet, more specifically on personal homepages published on the World Wide Web. Besides being a platform for many different activities, we noticed that the web also offers a space for users to present questions and exchange ideas on the meaning of life. The existence of many virtual communities on the Internet encourages discussion and sometimes intimate relations between strangers, which means that Internet conversations are more than merely 'cold' and 'impersonal' (Walther, 1996; Parks and Floyd, 1996).

Another, not unimportant aspect is the possibility of the Internet serving as a platform for processes and phenomena that are difficult to study under normal conditions. A few examples would be how markets adapt, how children learn outside classrooms or how organizations communicate (Kiesler, 1997). In certain respects this also holds true for the study of existential meaning. The process of meaning construction cannot directly be observed, the researcher thus will have to go to great difficulties to make it feasible for analysis. Meaning, and especially 'ultimate' or existential meaning, is often considered to refer to the most intimate and personal inner thoughts of an individual, whose ideas about the meaning of life are connected to a personal biography and (sometimes) disturbing and threatening experiences one is not willing to share with everyone. Moreover, meaning of life in modern secular times is thought to be of a subjective and privatized nature, disconnected of any interpersonal or societal debate (Luckmann, 1967; 1996; Berger, 1969). In this vein, the meaning of life and the Internet do not seem to be natural allies. For the Internet is, because of its accessibility, widely considered to be the most public (and democratic) medium of today, where exchange of information about almost every thinkable topic takes place. Because the Internet contains several environments where people spontaneously reflect on topics related to questions about the meaning of life, we suspect that the Internet could also be a platform for the exchange and 'bricolage' of meaning systems of individual Internet users. For this reason we regard the Internet as a 'space' for the expression of contemporary practices of the construction of existential meaning.

\section{Existential meaning}

Searching for and asking existential meaning questions embarks upon the ultimate realm of human understanding of life. Scholars of religious studies traditionally focus on questions and answers on the nature, goal 
and origin of life, the world and the place of humankind in it, as well as the meaning of illness, suffering, death and injustice. From our previous research on contemporary meaning systems (Hijmans, 1994) and personal meaning in the second half of life (Van Selm, 1998; Van Selm and Dittmann-Kohli, 1998), we learned that meaning consists of three interrelated core-elements: orientation, belief and experience, sometimes also known as motivational, cognitive and affective components of meaning.

'Orientation' reflects the everyday aspect of meaning. Individuals have plans and goals, and guidelines or rules they live by. It includes the evaluation of one's own capacities and the life one has lived so far, in the light of active realization of plans and goals in the future. The second element, 'belief', refers to opinions and ideas about the meaning of (one's own) life. Previous research shows that people use religious as well as secular constructs in answering existential questions (Hijmans, 1994). Orientation and belief are both active forms of the construction of meaning. The third element is 'experience', which is known as the passive aspect of meaning. The experience of meaning can happen at moments when no meaning-related questions were asked, for instance because there was no doubt, or at moments when one was 'opened up' and receptive. These moments of happiness or spiritual fulfillment 'happen' to people. In this case meaning is experienced as an affection, a being touched, which keeps life in motion (Peperzak, 1990; Van der Lans, 1992; Nies and Munnichs, 1989). The experiential element of meaning seems to be less reflexive in nature than the first two elements, which subsequently process and interpret experiences. In this way the three elements of meaning are intertwined in an ongoing process.

\section{The Internet}

As mentioned previously, the Internet can serve as a platform for the investigation of less visible processes, processes that are difficult to study. For instance, methodological references mention the employment of anonymous web-based electronic surveys in studies of deviant or covert behavior, or other sensitive research topics (Coomber, 1997). Our study on existential meaning on the Internet is focused on the recovery of another notoriously difficult topic; 'ideas' and constructs on the meaning of life, that normally cannot be observed. Besides in the content of meaning, we are also interested in the display of imagery or form of meaning on the Internet, as one of the typical uses of the Internet as a cultural artifact (Hine, 2000: 70). The Internet is commonly used as library, magazine rack, yellow pages and a forum for publication (Wallace, 1999). Individuals, organizations and companies construct websites 
containing information about themselves or other matters relevant to their audiences. Especially personal homepages often display features such as, 'information about me', 'a poem', 'links to my favorite photography sites' and 'links to homepages of my friends' (Wallace, 1999: 33). Because of the textual character of most websites, forcing the authors to construct a 'cognitive product' we expect to encounter an emphasis on the belief component of meaning.

\section{Personal homepages}

Personal homepages are online multi-media documents dealing with the question: 'Who am I?'. Homepages are personal and public at the same time, for they provide an insight into the personal lives of the authors (Chandler, 1998). Wynn and Katz (1997) actually found that personal homepages combine aspects of public life (education, profession) with private life (faith, beliefs, family, hobby, biography). Because the audience is unknown in advance, people aim at an integrated and holistic self-presentation. The thought that one's homepage could be visited by a possibly worldwide audience is, according to Wallace, together with a somewhat narcissistic drive to self-expression, reason enough to spend a lot of time on the construction and maintenance of a homepage. The actual number of visitors seems to be of less importance, and is usually not kept up to date (Wallace, 1999). According to Chandler (1998) the creation of a homepage is a constituent part of the construction of identity, resulting in a self-presentation of the homepage's author, that often will be 'under construction'.

As to the relation between the typical Internet phenomena of the personal homepage, as a consciously selected self-presentation and the cultural practice of meaning construction, a remark made by Wynn and Katz (1997) is important, and must be taken into consideration. They consider the making of a personal homepage as an expression of the integration of identity. The author reflects on his or her life as a whole and presents it as an ordered sequence of events. This description is closely related to the general function that Luckmann (1967) attributes to integrative meaning systems, which are supposedly present in all human beings. Individuals see and present their lives as an unity in which past, present and future are brought on one line. An all-encompassing meaning system provides the frame and the means with which to introduce this symbolic ordering, to see and present one's life to others as a morally relevant biography (Luckmann, 1967: 48). This means that one feels and can be held accountable to others for one's life. This is exactly what can be seen on personal homepages. And this is why personal homepages seem to be a promising place to conduct the present study 
into existential meaning on the Internet As a typical Internet phenomenon, personal homepages offer the opportunity to explore individual meaning systems, and the specific nature of existential meaning in this medium.

\section{Meaning on personal homepages from an action theoretical perspective}

The construction of meaning is the focal point of any study that draws upon action theory. This perspective, notably the sociology of knowledge (Berger and Luckmann, 1967) and symbolic interactionism (Blumer, 1969; Mead, 1934), provides a natural basis for our exploration of existential meaning in personal homepages. Generally speaking, objectivated everyday knowledge has its roots both in personal biography and culturally shared, internalized meanings. This knowledge is displayed on personal homepages, and witnesses processes of world construction and world maintenance. The construction and continuous restructuring of homepages can be thought of as externalizations of human action.

More specifically, human interaction and communication as core-elements of symbolic interactionism are only indirectly visible on personal homepages. But homepages are designed as a medium to communicate to others whatever seems to be of interest to make public to an unknown audience, and as a medium they are part of a meaning producing environment. It is not the interaction itself we will examine but the means by which a communicator, who has a history as a recipient of other media and other homepages in searching for answers to questions of the meaning of life, intends to convey his/her views to others. As said, personal homepages show accounts of one's life to oneself and to others, and as such represent a form of active goal directed media-use. A as form of social action, we could expect that they take into account and are oriented by the behavior of others.

In connection with the action theoretical frame of reference formulated by Renckstorf (1994), Renckstorf, McQuail and Jankowski (1996) for media use and applied to, for instance, the use of television news (Renckstorf and Wester, 1999) we will discuss in more detail how the study of symbolic content of personal homepages can be understood in action theoretical terms. As we mentioned earlier, homepages are the result of external action. As a communicator, the author of the homepage produces and selects information. The content of homepages consists of carefully constructed subjective meaning and is the result of internal processes. The internal action of defining the situation is vital for the construction of homepages. From a theoretical point of view the homepages in our research sample contain the provisional solution of the problem of the meaning of life, therefore we consider them as one of 
the phases in the ongoing process of solving the ultimate problem of existential meaning.

In short, media use in our contribution comes down to the active deployment of the Internet as a medium, and its multi-medial technical possibilities, as an extension of the person, both as an individual and a member of society. The construction of existential meaning can adequately be grasped in terms of action theory.

Our study will focus on three questions: 1) Which elements of existential meaning arise in the practice of meaning construction on the Internet, and more specifically on personal homepages?; 2) In what way can this existential meaning be characterized?; 3) What is the meaning of the results in reference to the action theoretical perspective?

\section{Methods}

Two popular search engines ${ }^{1}$ were used in order to identify websites devoted to existential meaning. Two searches with the search term 'meaning of life' resulted in 63390 and 28622979 'hits' respectively. We derived our research material from this pool of websites, following the principle of theoretical sampling, in the following way. The first 210 websites of each search were printed on paper, resulting in a list containing 420 websites. A number of these websites were categorized as personal homepages. The personal home pages were stored, by means of a hyperlink, on the site of a groupware product, to which only the authors had access. In this way we could retrieve the sites easily during the phase of analysis. The employment of the English search term 'meaning of life' has far reaching consequences for which websites are incorporated in our research material. Websites published in another language are excluded, as well as sites which include a discussion on existential meaning, but not explicitly labeled as such; i. e., in a way conceivable to search engines.

\section{Analysis}

The analysis was undertaken in two steps. The first step aimed at mapping the field of websites indexed of the search term 'meaning of life'. A global system of categories was developed, based on the types of websites present in our material $(\mathrm{N}=420)$. Both authors worked independently at first and later collectively, in order to develop suitable descriptions for the categories of websites. By comparing and discussing the categories we were able to create an intersubjective categorization, which is presented in Table 1. As this table shows, not all the websites found were personal homepages. 
Table 1. Categorization of websites.

\section{Category}

Personal homepages

Advertisements (regarding books, CD's, video tapes)

Traditional religious organizations: churches, groups, sects

New age organizations, meeting place for exchange of ideas, documents,

quotations

Contributions to discussion groups

Related to Monty Python

Jokes, humor, parody

Academic centers, universities, course information

Spontaneous collections of idea's on existential meaning

Instructional sites, search engines regarding specific topics

Art (film, paintings, play)

(Horror) stories

Spiritual professionals and experts (no church)

Websites (other than homepages) not categorized

Not related to search term

Not available on server anymore

Rest categories (including doubles)

Total

The personal homepages formed the largest category. In our study, personal homepages were conceived as those sites that typically resemble a homepage (websites containing pages about 'my CV', a guest book, information on friends and family, hobbies). In addition, websites that were labeled as such by the author and sites devoted to the author's personal story or vision, were also categorized as personal homepages.

Table 1 shows that, in addition to personal homepages, commercial websites concerned with the selling of books, CDs and videotapes also devoted space to existential meaning. The same is true for websites of religious organizations, New Age organizations, and of professionals working in the field of spirituality. In addition, we found websites of universities, discussion groups and other virtual meeting places devoted to the topic of the meaning of life. Less serious websites were also found, such as websites devoted to Monty Python's movie, or to jokes and fantasy stories about the meaning of life. Finally, we found a number of websites on which existential meaning was interpreted in an artistic way.

The second step of analysis aimed at describing and typifying the way in which existential meaning was seen or explained on personal homepages. This second step was conducted for only for those websites which could be considered personal homepages, as our research question focused on this type of websites. In total we thus analyzed 88 websites. We 
tried to find answers to a number of questions, both descriptive and interpretive in nature, that were addressed at each personal homepage (unit of analysis). The observation scheme was developed in the course of re-reading the empirical material. Hence, the questions link up with the empirical material, and were intended to contribute to a typology that reaches beyond a mere description of existential meaning on personal homepages.

Of those websites that were considered personal homepages in the first 'rough categorization' (see Table 1), 42 web were found suitable for study. These homepages were still available on the server, they qualified for the criterion 'personal', and an indication of the search term 'meaning of life' could be easily identified.

The ongoing reduction of research material described above is a way of theoretical sampling and implies that, finally, only a selective pool of homepages was examined. Our conclusion only bears on this selection of sites. Another limitation of this study is that it involves an analysis of already existing material, namely electronically published textual and visual materials sometimes furnished with audio- and video elements. The author's expression of existential meaning is examined as a document, on which we did not exercise any influence. Hence, the examination is best described as a qualitative content analysis, and more specifically as interpretive analysis (Hijmans, 1996).

\section{Description of personal homepages}

The personal homepages examined differed in size. Half of them consisted of 10 to 20 web pages, while 11 sites contained 20 to about 100 web pages (in one case even up to 400), and another 11 contained less than 10 web pages.

Table 2. Number of web pages constituting personal homepages.

\begin{tabular}{ll}
\hline Size (in number of web pages) & \\
\hline $20+$ & 11 \\
$10-20$ & 20 \\
Less than 10 & 11 \\
\hline Total & 42 \\
\hline
\end{tabular}

The design of the personal homepages examined was quite divers. Even though the textual information on the websites was the main focus of our examination, some attention was paid to design characteristics, such 
as background pattern, color, font, illustrations, pictures, audio and video. We expected these characteristics to disclose aspects of the experiential component of existential meaning, as this component might be expressed in an aesthetic, instead of a textual way. A general examination of design shows that three quarters of the websites are designed using color, background patterns, pictures or other illustrations. In some cases this resulted into a stylistic composition, in other cases into an arbitrary collection of elements. Ten homepages were furnished with multi-media tools such as banners, moving objects or movie-clips, music or a voice. The musical elements used were in all cases instrumental, quiet or joyful, and meant to provide a background sound while reading texts reflecting 'deep thoughts' on existential meaning. On nine sites, very little use is made of the possibilities of Internet technology; these sites are mainly textual in nature. Later, we will describe a possible correlation between types of existential meaning and design aspects of the personal homepages.

Table 3. Design of homepages examined.

\begin{tabular}{lr}
\hline Design & \\
\hline Text only & 9 \\
Composition & 23 \\
Composition including video & 4 \\
Composition including audio & 5 \\
Composition including video and audio & 1 \\
\hline Total & 42 \\
\hline
\end{tabular}

Table 4. Gender of authors of homepages.

\begin{tabular}{lr}
\hline Gender & \\
\hline Male & 33 \\
Female & 7 \\
Coproduction & 1 \\
Unknown & 1 \\
\hline Total & 42 \\
\hline
\end{tabular}

Regarding the backgrounds of the authors of the personal homepages in our sample the following came to the fore. The authors were mainly men (Table 4), between the ages of 21 to 40 years old (Table 5), and residing in the US (Table 6), thus resembling the average Internet user (e. g., Van Dijk, 2000). Young (white, well-educated) men from the wealthiest part 
of the Western world are over-represented amongst the users of the Internet, and (hence) also in our sample of websites. This implies another limitation of our study, as the existential meaning of only this specific group of authors is examined.

Table 5. Age of authors of homepages.

\begin{tabular}{lr}
\hline Age & \\
\hline $10-20$ & 4 \\
$21-30$ & 11 \\
$31-40$ & 10 \\
$41-50$ & 6 \\
$51+$ & 4 \\
Age unknown & 7 \\
\hline Total & 42 \\
\hline
\end{tabular}

Table 6. Residence of authors of homepages.

\begin{tabular}{lr}
\hline Residence & \\
\hline US & 33 \\
Canada & 2 \\
Norway & 2 \\
Australia & 1 \\
UK & 1 \\
Unknown & 3 \\
\hline Total & 42 \\
\hline
\end{tabular}

The prominence of existential meaning varied across the personal homepages examined (Table 7). Whereas on some sites existential meaning was the central theme (17 sites), on other sites the topic was treated as one of many subjects present (16 sites).

Table 7. Prominence of existential meaning on the homepages examined.

\begin{tabular}{lr}
\hline Prominence & \\
\hline Central theme & 17 \\
One of many subjects & 16 \\
Single question & 6 \\
Joke & 2 \\
Not recognizable & 1 \\
\hline Total & 42 \\
\hline
\end{tabular}


The re-reading of our research material resulted in the identification of various guidelines on how to construct or discover life's meaning, or, more generally, how to deal with life (on 29 of 42 homepages). In table 8 these guidelines are summarized.

Table 8. Inventory of practical guidelines for a meaningful life.

Practical guidelines

Believe in God, live according to gospel, read bible, pray, be baptized

Search for meaning within yourself:

- through everyday activities (a. o. giving and seeking support, reading poems, enjoying nature

- by your own philosophy of life, wisdom

- by thinking rationally, scientifically

- by techniques for mental improvement (intense observation, fast reading, better reasoning)

- by studying Tao and using insights for a new way of living

- by setting a goal

- without further explanation

Orientation on the future of world/humanity; transcendence of direct life world Study the origin of life (by scientific references)

Carry out developmental tasks for life improvement No guidelines

The internal search for meaning is the most important guideline (16 sites). Visitors are advised to grasp the meaning of life by "working on their inner selves'. By creating meaning in life, meaning of life can be experienced. This 'working on the inner self' can take several directions; e. g., to live life from a personal philosophy of life or to set goals in life. Others advise to raise one's consciousness, for instance by reflecting on the value of everyday experiences, or the working of the human psyche to improve mental abilities. The idea is that by an intense way of thinking, the meaning of life eventually will become clear.

The display of activities within the Christian tradition is a second category of guidelines. This category contains the advice to serve God, or to live in accord with the gospel of Jesus Christ, but also more practical advice such as to read the bible, or to get yourself baptized. The rest of the guidelines relate to ideas of putting your life in service of a collective goal, or trying to discover an encompassing plan of life. On one of the sites this was substantiated with understandings from the evolution theory; on another one with the idea of a 'standard sequence of life', distinguished by inevitable developmental tasks that have to be fulfilled. The 
three components of meaning: orientation, belief and experience are combined. Experiential elements and daily actions are presented to others as conclusions based on beliefs and reflection.

A more general finding concerns the use of quotes on homepages. The authors of personal homepages sometimes indicate that words and thoughts of others (ranging from long deceased classical philosophers tot modern pop stars) were helpful in answering questions of existential meaning.

"Someone close to me once said, and I'm paraphrasing here, "Don't read me a quote, I want to hear you talk." That meant a lot to me and I'll never forget it. However I can't talk to everyone and maybe you don't want to listen to me. Quotes are wonderful. The meaning can be changing and sometimes a timely quote can be wonderfully uplifting.

I like to collect quotes cause they represent thoughts and emotions that my experiences have not yet provided to me. I have roughly organized them. For each sub page the newest are always at the top, so you can easily tell if the page has changed" consulted 25-01-01).

There are more ways of referring to existing ideas, literature and traditions. We came across more or less frequent use of hyperlinks, in more than three quarters of the homepages hyperlinks were found, as the next table shows.

Table 9. Number of hyperlinks to external sites.

\begin{tabular}{lr}
\hline Number of hyperlinks & \\
\hline 15 or more & 11 \\
5 to 14 & 18 \\
1 to 4 & 4 \\
None & 9 \\
\hline Total & 42 \\
\hline
\end{tabular}

Hyperlinks establish a connection with sources elsewhere on the World Wide Web. We were interested in finding out the different types of sources the homepages in our sample related to. We made an inventory of the following sources of wisdom that were used in answers to questions of the meaning of life (table 10).

The bible, symbols and concepts of Christian faith turned out to be an important source (13 sites). Other sources were humanism (5 sites), and concepts from new spiritual awareness groups (9 sites). Philosophy, for instance existentialism, was found on 7 sites. Several sites (8) used scientific concepts from social sciences or evolution theory. One last category referred to literature and lyrics (4 sites). 
Table 10. Inventory of sources and traditions. ${ }^{3}$

Sources and traditions

Christianity, quotes from the bible, Jewish tradition

(Anti-religious) humanism, spiritual ecology (e.g., Greenpeace), social movements (feminism, civil rights)

References to existentialism, (moral) philosophy (e. g., Epicurus, Plato) philosophy of science, reason. Other thinkers and writers: Freud, Russell, Cervantes, Epictetus, Ellis

Evolution theory, Darwinism, evolution psychology, Dawkins, (social) scientific concepts

Concepts and quotes from new spiritual awareness (Yin/Yang, tai chi, Tao, karma, pagan religion, hypnosis, holism, Para normality, agnosticism) 'new Jews': combination of religions

Literature (Herman Hesse, Huxley), music, lyrics, quotes

4

Total

A final question that puzzled us was the reason why the authors decided to publish their life stories, personal views and advice to others. Our observation scheme included a question about the typification of the site in general, including motives or goals. Some authors were clear about their motives, while others were quite inconclusive. Although this aspect obviously needs further elaboration, for instance by online interviewing, we found that clear goals were formulated by converted Christians, and other authors who sometimes eloquently drew from ideological traditions. Though not impersonal, the personal element remains in the background, and was sometimes difficult to recover. For instance the author of a 'Christian resources page' ${ }^{4}$ is decisive on the uselessness of personal information. He considers his goal to be communication with the masses, and not just to save himself but also others. At the same time he makes several ironic remarks on his ambition to be seen on the web, as he welcomes any awards coming his way.

Authors that are less convinced of their beliefs tend to be more personal. They give testimony of their soul searching and personal growth. The support they found in thoughts, books or music is made public, sometimes in the form of an online diary. Motives for the production of these kinds of ego documents are not always clear. Some authors state their intentions to make themselves known in all important facets in testimonials of mere personal biographies ${ }^{5}$. Additionally, we found that authors try to elicit and welcome reactions from others, which suggests that the possibility of one's homepage being visited by unknown others is a reward in itself. This is even more clear when counters keep a check of the exact number of visitors, as we actually found in several cases. It 
seems that this form of self-expression discloses a somewhat self-centered, though very human motive of affirmation of one's existence by others.

Summarizing our results so far, we could say that in our sample the presentation of existential meaning forms a constituent part of self-presentation in personal homepages. Three quarters of the homepages can be called extensive and in many cases the authors have made creative and artistic efforts. The homepages seem to be constructed by individuals who wanted to use the potential of the medium for (self) expression, and in doing so in one way or the other turned to the theme of existential meaning. Our basic assumption that meaning is connected to everyday life seems to be justified, as can be seen in the number of guidelines we found (16). Meaning takes on an aspect of orientation and belief at the same time, while the guidelines partly concern experiences. Motives of authors are (a combination of) altruistic and narcissistic intentions.

\section{A typology of existential meaning on homepages}

The above description of sites depicts a global view of their owners and the ways in which existential meaning is represented on personal homepages. In this section we will characterize the symbolic content and the different directions existential meaning takes on in these homepages.

Initially we created a broad dichotomy. On the one hand, questions of existential meaning were placed in an encompassing perspective of a transcending nature and non-human origin. Examples are Christian faith or the cycle of nature and its cosmic powers. On the other hand, meaning of life was associated with human experience: meaning of life can be experienced by searching for meaning in life. The experiential component of meaning is stressed, as was already visible in table 8 . The tips and guidelines presented there show the different directions of this distinction. We compared the whole of every homepage in respect to the specific directions of the meaning of life, be it questions or answers, ideas, visions, stories, guidelines etc. In the following table 11 the two directions were labeled as superhuman (17 sites) and human (18 sites).

Table 11 is an ideal typical construction, not an empirical typology. Ideal types are specific cultural meaning systems, acquired by one-sided overstressing of one or more points of view (Lemmen, 1977: 57). Ideal types in the Weberian sense serve theoretical goals directed at understanding phenomena under study, by focusing attention on one or several characteristics. This means that theoretical types of a typology will be hard to find in their pure form in empirical data because this tends to be less clear. In our case, this means that most sites combine several elements. We assigned a type of orientation to each homepage, on the 
basis of the prevailing direction of existential meaning and of the internal coherence of elements.

The homepages are qualified by the dimensions natural - supernatural and human - superhuman. Besides the already mentioned distinction human/superhuman, we also discovered a distinction we labeled: natural/ supernatural. Taken together, the supernatural and superhuman remind us of the 'otherworldly' orientation of religious meaning, whereas the natural/human combination reminds us of the 'innerworldly' orientation. We believe this well-known distinction can be further qualified by the addition of the supernatural/natural distinction, which opens up the possibility of a supernatural ultimate goal of life of human origin (Hijmans, 1994: 204). The supernatural is not known to the laws of nature, but in the context of existential meaning this does not necessarily imply a sacred or divine character (Berger, 1969: 27). Especially in modern times, human projections of social scientific and utopian ideals enable man to transcend his individual nature to encompass the whole of mankind. Individual existence is subordinated to these ideals, which grant it an ultimate ground. These ideals are, as the ways of God, unnatural and have to be 'invented'. As such they are not fully known, and can only be approached by social and psychological theories that legitimate human existence. As in the religious interpretation of life there is an external interference in nature that lends meaning and orientation to human life.

Opposite this orientation we find the natural approach in which human interference is unthinkable. Individual life in itself is quite a meaningless fraction of human existence in the universe. Life takes its natural (evolutionary) course and the forces man has to face are indifferent, 'blind' processes that unfold in spite of human presence. These blind natural laws (dis)organize human life and grant it its existential meaning. This is a superhuman, but natural form of existential meaning in which humans are part of a natural arrangement.

Finally, there is the human variation of the natural orientation. We already mentioned the emphasis on human experience. There is mention of authenticity and quality of life experiences, that enable the experience and subsequent interpretation of existential meaning of life. We called this the 'anthropocentric' experience, in which individuals try to transcend their ego by opening up to essential life experiences that in themselves lack metaphysical legitimacy. Experience of the fullness of life grants meaning. This leads to the following results.

The table shows that 37 sites could be classified, 5 sites could not be interpreted because meaning was too inclusive, diverse or without clear direction.

A total of 14 homepages were classified as the superhuman-supernatural type labeled as divinelreligious. Christianity dominates this type; 
Table 11. Typology of orientation of meaning in personal homepages.

\begin{tabular}{llrlrr}
\hline & Supernatural Creator/goal & \multicolumn{4}{l}{ Natural experience/Blind process } \\
\hline Superhuman & Divine, religious & 14 & Cosmic, natural powers & 3 & 17 \\
Human & Social utopian & 5 & Anthropocentric experience & 15 & 20 \\
\hline Total & & 19 & & 18 & 37 \\
\hline
\end{tabular}

twelve pages refer explicitly to the bible as main inspiration to find meaning. Existential meaning is already 'out there', and in need of discovery. The meaning of life is part of an encompassing plan of God or a nameless creator. Remarkable are the testimonials of the converted (' $I$ believe and I stand for it'), ${ }^{6}$ they carry the message with great personal fervor and conviction and intend to persuade the audience of their homepages to find salvation, 'Be, pray, know'. ${ }^{7}$ Many present Christian guidelines for life $^{8}$ or examples of what healing faith has brought, for instance in dealing with personal catastrophes such as suicide. ${ }^{9}$ The styling of almost all sites is quite skillful, with color, photos and, in some cases, music. In terms of the three core elements of existential meaning (orientation, belief and experience), the belief element is stressed mostly.

In the anthropocentric type of meaning the most important elements are experience and orientation. This category is diametrically opposed to the former religious type, because it combines human and the natural dimensions. We placed 15 homepages in this ideal type, which advocates the idea that meaning of life can be found within; i. e., in inner experience. Existential meaning, therefore, has many different manifestations. Some pages stress the full employment of mental capacities and the full (scientific) understanding of human nature and experience, sometimes it is said that there is no real (cognitive) answer to questions of the meaning of life, but that the silence after posing the question contains the answer. Life itself is the meaning of life, including an open mind for the everyday beauty of life, ${ }^{10}$ and the enjoyment of little things and encounters with others. The 'here and now' and 'happiness' are frequently used concepts that illustrate the immediate experience and the receptiveness to meaning in the context of everyday life. The human element can be seen in the responsibility for one's own happiness, as said meaning lies within the life performance:

"Meaning in life comes from what we do with it. Meaning of life comes from the act of living." (http//www.users.uniserve-ca/\%7erfrisen/mean life.html, consulted 25-1-01) 
The styling varies among the pages. Some are purely text based, but others display professional designs. The authors of three sites commemorate Internet technology as a means to publish and discuss ideas on the meaning of life. ${ }^{11}$

The other two types are combinations of former ones. The socialutopian type is supernatural in orientation but human at the same time, while the cosmic type assumes natural 'blind' processes from a superhuman nature. In our research sample we found that 5 sites fitted within the social-utopian type. Goals are mentioned such as 'doing something good in the world', to 'look beyond your own possessions and family', ${ }^{12}$ or 'think about the future on a world scale', ${ }^{13}$ 'take responsibility for society'. ${ }^{14}$ As in the other human type, responsibility is stressed. Here is not the individual but an encompassing whole such as mankind or society at stake. Individuals have to overcome their natural drives for the benefit of the collective. The style of these sites is calm, somewhat dull and without fantasy. They contain mainly text and make hardly any use of multimedia technology. Of the core-elements of meaning mainly orientation, in combination with belief, is stressed: ideological goals are the guidelines for everyday action.

Finally the cosmic type was encountered only three times. The main theme here is that life has no intrinsic meaning because it is part of a natural order. This stresses mainly the belief element of meaning, there is no connection to the orientation or experience element. One of the sites suggests that life is part of the evolution. ${ }^{15}$ Another claims that life is in perpetual motion, that will always exist with the preservation of energy. ${ }^{16}$ In this category, the (natural) sciences are a main source of inspiration. The style of the sites differs from exclusively textual to professionally styled with moving texts.

In short, the characterization of the symbolic content of personal homepages with respect to existential meaning resulted in four ideal typical orientations. Two dimensions are typical: the human/superhuman and the natural/supernatural. By crossing the dimensions four ideal types emerge, that two by two share common characteristics. In the two human types, ideals and experiences are important, in the two superhuman types an encompassing transcendent order superimposes itself on man. The two supernatural types share a common belief in an external goal that directs life, and the two natural types share that goals have to be internal, and derived from individual experience, or from a very distant order in universe in which a single human life is practically insignificant. We see further similarities and differences in orientation between the superhuman and human orientations. The human orientations share in their ideals and experiences an orientation to the future, while the superhuman look back to the past and the cause and origin of man. 
We found that there are 19 cases in the supernatural column and 18 in the natural, while there are 17 cases in the superhuman row and 20 in the human row. No sub-dimension seems to dominate. But when we take a closer look, we see that two combinations of dimensions and opposite types certainly have dominant traits: the superhuman/supernatural or divine-religious case (14) and the human/natural or anthropocentric case (15), whereas the utopian and cosmic orientations lag behind with 5 and 3 cases. This does not mean that they are unimportant, they merely represent a corrective to the view of a simplistic distinction between religious and humanistic worldviews, the dichotomy we started with in our interpretation, which is also known as 'otherworldly' and 'innerworldly' orientations to the meaning of life. There are more possibilities for the supernatural than the divine and there is more to the natural than human life itself.

\section{Conclusion}

In this paper we presented an exploratory study aimed at characterizing existential meaning on a sample of personal homepages. With regard to our research questions we examined structural characteristics, as well as an interpretation of content. The instrumental aspects of these homepages will follow in the concluding remarks.

Although the domains of existential meaning and the Internet do not seem to have much in common, our examination showed that 'the meaning of life' featured either as a main, or a secondary topic on 42 personal homepages, which were derived from a initial sample of 420 websites. We found that the most of the authors of the personal homepages examined were male, between 20 and 40 years old, and residing in the US. With regard to other structural characteristics we discussed styling, number of web pages belonging to each website, and number of hyperlinks to external sites.

The content concerned with existential meaning encountered on the personal homepages, could be interpreted as a typology of ideal types constituted by the dimensions human-superhuman, and natural-supernatural. We formulated the following four ideal types: a divine-religious, a cosmic, a social-utopian, and a anthropocentric orientation of existential meaning.

Several conclusions could be drawn from this result. First, our examination showed that the belief component (emphasized in the divine-religious type) as well as the orientation and experiential components (emphasized in the anthropocentric type) of meaning come to the fore on personal homepages. Hence, in spite of the textual character of most websites that forces the construction of a cognitive product reflecting 
authors' thoughts, the medium also appeared to invite the expression of the orientation and experiential components of meaning.

Second, the ideal types show that the personal homepages provide traditional answers in that a relationship is conceived between human existence and an encompassing supernatural, divine plan. Hence, the authors of the personal homepages examined are not, per definition, secularists, and technological innovations are not hostile to tradition. In addition to these traditional answers, we found ones that reflect existential meaning in which individuals also transcend themselves and the level of everyday experiences, but, instead, emphasize authentic life experiences that are used in order to become a better and wiser person. The types divine-religious and anthropocentric were most clearly represented in our research material, whereas the utopian and cosmic orientations represent a corrective to a dualistic view of meaning as either religious or secular.

Third, in the light of an action theoretical approach, three results are important: the three components of meaning, the featuring of guidelines and hyperlinks on personal homepages, and the intentions of authors to publish their personal views. To begin with a small but insightful observation; the three components of meaning we distinguished in advance and found useful for our analysis relate to the classical action theoretical concept of structures of relevancy. Belief and experience coincide with the cognitive and affective aspects of knowledge Schutz distinguished in his conceptualization of structures of relevancy, while orientation stands for the definition of the situation. In our opinion, research on the question of meaning of life could gain by further elaboration of this relation.

Hyperlinks offer authors of homepages an opportunity to link ideas and visions to those of others. Wynn and Katz (1997) emphasize this functionality of hyperlinks; "The links allow in-depth views of particular themes, thus providing for more dimensionality than anything that can be achieved on a page" (318). Hyperlinks are a means to express and mediate existential meaning to others, as they allow for the relationship between individuals' ideas and those of others to become visible and retrievable. The network structure of personal homepages represents multiple sources of existential meaning. In our opinion, these sources have become endless, inasmuch as Internet technology facilitates access to an innumerous variety of sources. The World Wide Web offers space for all sorts of beliefs and orientations, and our research material somewhat unexpectedly showed that institutional answers to questions regarding existential meaning co-exist with more or less idiosyncratic visions. Not only via hyperlinks, but also by means of guest books or e-mail responses, relationships with others are initiated and maintained. 
From a general action theoretical perspective the use of hyperlinks and the presentation of guidelines indicate relations with the broad societal context and exposure to mediated messages of others on the web. On the one hand personal homepages represent the actors' perspective on life as it crystallizes in styling and symbolic content. As a product of internal and external action, the unique content of every homepage refers to the personal stock of knowledge, and the subjective hierarchical system of relevancies that show a typical personal pattern of meaning. On the other hand, however, as said, interpretation is never entirely individual. As Blumer stated (1969: 5), meaning is a social product, it constitutes part of the identity of the individual as a participant in society. As such the social stock of knowledge provides help for the construction of personal homepages, as can be seen in numerous hyperlinks and traditions that the authors refer to. The presentation of guidelines reveals, as do the hyperlinks, a thoroughly social action, taking into account the response of invisible others. This mechanism of role taking refers to symbolic self-interaction, that anticipates an imagined reaction of invisible others, and reflects past experiences with others at the same time.

The intermingling of personal and societal factors is also visible in another concept, related to the internal action of defining the situation, namely intentionality. On personal homepages intentionality of authors to publish their personal views is mostly implicit. But we found that intentions could be (partly) reconstructed, they could become apparent through the guidelines and rules, or through offering advice or inspirational thoughts presented for the benefit of others. More self centered motives such as to attract as many visitors as possible, to gain an award, or at least responses from others could also be reconstructed from the content of a website. In fact, we found that authors displayed multiple signs of orientation to others, and that intentions to publish their views represented an extension of this orientation and a combination of selfless as well as self-centered motives. Hence the title of our contribution, for the intentionality of authors of homepages covers a broad range between altruism and narcissism.

From an action theoretical standpoint we have thus achieved an insight on the widespread idea that existential meaning nowadays is individualistic, subjective, privatized and invisible. As mentioned earlier, the network structure makes visible both an ideological and social 'anchoring' of existential meaning into traditions and movements on the one hand, and a network of like-minded persons on the other hand. Although the medium, and more specifically the personal homepage, offers an outlet for the expression of rather individualistic forms of ultimate meaning, it is at the same time a space in which these forms are immediately linked up with vested traditions, collective ideologies, and social 
networks. We think that the practice examined here, including the employment of hyperlinks, can be labeled as an informal way of constructing answers to questions regarding existential meaning taking place in the virtual public arena of the Internet.

Therefore, both the construction of existential meaning and the use of the Internet are to be considered as isolated or alienated. Furthermore, existential meaning in personal homepages is not found to be exclusively cognitive-reflexive in nature, life experience is an additional source of ultimate meaning, as are traditions of multiple origins. In sum, the specific nature of existential meaning on personal homepages on the Internet resides in: a) the network structure of the Internet enabling hyperlinks to multiple sources, thus adding depth or multiple dimensions to personal documents; b) the opportunity for 'bricolage' of existential meaning systems from sources widely differentiated with respect to content; c) the styling and design of symbolic content; and d) traditions and life experiences as elements of existential meaning.

Finally we will end with a few closing remarks on some difficulties on Internet research. As stated, in this study the conclusions are based upon an examination of a selection of web documents reflecting authors' thoughts on existential meaning. It took us a great deal of effort to separate 'the wheat from the chaff'. Only half of the sample of homepages contained sufficient information to conduct our comparative analysis. The homepages we considered as insufficient for analysis hardly elaborated on the topic. We think that the chaotic, unordered and unannotated way information is present on the World Wide Web is an important ground for the necessity of ongoing reduction of research material. This means that the analysis of (parts of) the content is a job requiring much effort, even before the actual analysis can start. Interviewing the authors of homepages could overcome some of the difficulties we encountered. In this study, no attention was paid to the internal processes on behalf of the authors preceding the construction of personal homepages. In further study (e-mail) interviews will be conducted in order to examine motivations for the construction of personal homepages containing expressions of existential meaning. In this way, not only more of the actor perspective and the internal actions will be reconstructed, also more insight could be gained in the role of exposure to other homepages, and other media and the accounts of authors regarding style and design of their homepages.

\section{Notes}

1. We used the search engines Alta Vista and Infoseek.

2. 'Composition' is due in case a personal homepage is furnished with color, a background patterns, pictures and/or illustrations. 
3. Because one site referred to more than one tradition, the total exceeds 42 .

4. http://www.geocities.com/area51/5963/meaningoflife.html

5. http://www.stjarna.com/

6. http://www.gurlpages.com/bisquick/christian.html

7. http://www.geocities.com/area51/5963/meaningoflife.html

8. http://www.thebigquestion.com/index.html

9. http://www.jaredstory.com/meaning_of_life.html

10. http://www.awaken.org/trans/970124.html

11. e. g., http://www.users.uniserve-ca/\%7erfrisen/meanlife.html

12. http://www.stud.ntnu.no/\%esverreno

13. http://www.progressivehumanism.com/meaning.html

14. http://www.jimn.org/write.meaning.text

15. http://www.iup.edu/\%7ergendron/links.htmlx

16. http://www.telusplanet.net/public/bwholmes/reapir.htm

\section{References}

Berger, P. L. (1969). The sacred canopy: Elements of a sociological theory of religion. New York: Doubleday.

Berger, P. and Luckmann, T. (1967). The social construction of reality. A treatise in the sociology of knowledge. New York: Doubleday.

Blumer, H. (1969). Symbolic interactionism. Perspectives and methods. Englewood Cliffs, NJ: Prentice Hall.

Chandler, D. (1998): 'Personal home pages and the construction of identities on the web' [WWW document] URL http://www.aber.ac.uk/media/Documents/short/ webident.html [Consulted 30-5-2001]

Coomber, R. (1997). Using the Internet for survey research. Sociological Research Online, 2 (2). http://www.socresonline.org.uk/socresonline/2/2/2.html

Dijk, J. A. G. M. van (2000). Widening information gaps and policies of prevention. In K. Hacker and J. van Dijk (Eds.), Digital democracy. Issues of theory and practice (pp. 166-183). London: Sage.

Gergen, K. J. (1991). The saturated self. New York: Basic Books.

Hijmans, E. J. S. (1994). Je moet er het beste van maken: Een empirisch onderzoek naar hedendaagse zingevingssystemen. Nijmegen: ITS.

Hijmans, E. (1996). The logic of qualitative media content analysis: A typology. Communications, 21 (1), 93-108.

Hine, C. (2000). Virtual ethnography. London: Sage.

Kiesler, S. (Ed.) (1997). Culture of the Internet. Lawrence Mahwah, NJ: Erlbaum.

Lans, J. van der (1992). Zingeving en levensbeschouwing. Een psychologische begripsverkenning. In F. Eijkman (Ed.), Weer zin leren. Over levensbeschouwing en educatie (pp. 7-20). Best: Damon.

Lemmen, M. (1977). De godsdienstsociologie van Max Weber. Nijmegen: Dekker and Van de Vegt.

Luckmann, T. (1967) The invisible religion: The problem of religion in modern society. New York: Macmillan.

Luckmann, T. (1996). The privatization of religion and morality. In P. Heelas, S. Lash, and P. Morris (Eds.), Detraditionalization. Critical reflections on authority and identity. (pp. 72-86). Oxford: Blackwell.

Mead, G. H. (1934). Mind, self and society. Chicago, IL: The University of Chicago Press.

Nies, H. L. G. R. and Munnichs, J. M. A. (1989). Het begrip zingeving. In J. A. Munnichs and G. Uildriks (Eds.), Psychogerontologie (pp. 53-57). Deventer: Van Loghum Slaterus. 
Parks, M. R. and Floyd, K. (1996). Making friends in cyberspace. Journal of Communication, 46, 1, 80-97.

Peperzak, A. (1990). Zoeken naar zin. Proeven van wijsbegeerte. Kampen: Kok Agora.

Renckstorf, K. (1994). Mediagebruik als sociaal handelen. Nijmegen: ITS.

Renckstorf, K., McQuail, D., and Jankowski, N. (Eds.) (1996). Media use as social action. A European approach to audience studies. London: Libbey.

Renckstorf, K and Wester, F. (1999). An action theoretical frame of reference for the study of TV news. Communications, 24 (1), 39-60.

Ruffin, J. (1984). The anxiety on meaninglessness. Journal of Counseling and Development, 63, 40-42.

Selm, M. van (1998). Meaninglessness in the second half of life. Nijmegen: Nijmegen University Press

Selm, M. van and Dittmann-Kohli, F. (1998). Meaninglessness in the second half of life: The development of a construct. International Journal of Aging and Human Development, 47 (2), 81-104.

Wallace, P. (1999). The psychology of the Internet. Cambridge: Cambridge University Press.

Walther, J. B. (1996). Computer-mediated communication: Impersonal, interpersonal and hyperpersonal interaction. Communication Research, 23 (1), 3-43.

Wynn, E. and Katz, J. E. (1997). Hyperbole over cyberspace: Self-presentation and social boundaries in Internet home pages and discourse. The Information Society. 13 (4), 297-328. URL: http://www.slis.indiana.edu/TIS/articles/hyperbole.html (Visited 30th of May 2001). 